\title{
Urban Networking vs. Smart City
}

\author{
Carmen Beatrice, PĂUNA, \\ Institute for Economic Forecasting, Bucharest, Romania, \\ carmenbpauna@gmail.com
}

\begin{abstract}
Taking into consideration that the development of strong partnerships involving local citizens, civil society, the local economy and the various levels of government is an indispensable element for an Integrated Sustainable Urban Development, our paper is focusing on the role of an appropriate urban networking in the relationship with the objectives of a smart city. In this context, the Romanian good practices - as Oradea city - are worth to mention. In compliance with Europe 2020 Strategy's objectives there will be discussed the particularities of urban networking in order to strengthen the resilience of cities, and to ensure synergies amongst the investments supported by European Structural and Investment (ESI) funds. According to economic literature the urban network is not a funding instrument but a way for cities to share feedback on the use of these new approaches. The estimated results of our research are related to the conclusion that the urban networks act as a forum for capacity building and exchange between the cities pioneering new techniques and developing integrated investments.
\end{abstract}

Keywords: sustainable urban development; smart city; learning city

JEL Classification: R50, R58

\section{Introduction - Concept of urban areas}

The competitive approach to urban land management is one of the most sustained land arrangement policies in Europe and also in the world.

There is proof of the effect which buildings have on the environment, from the writings of Vitruvius down to the notes of William Morris, about the negative impact on nature which the fast rate of industrialization and urbanization had by the end of the 19th century. 
The possibility of having constructions with a lower energy consumption and the benefits of solar energy, for instance, became obvious in the 20th century. The impact of buildings on environment was debated extensively in the 60 'ties and 70'ties when the bases for the present sustainable architecture were laid. It is estimated that almost half of the carbon dioxide emissions in the world are caused by the buildings, however, not only the daily consumption of energy in the buildings but also the transport of people and goods between the buildings is responsible for the energy used. Similarly, the technological process in the extraction and processing of materials, as well as in transporting them to the site is responsible for energy consumption. All this has in view the costs incurred by a building during its life and the effect of the attempt to reduce the impact of humanity on Earth.

An urban area is an area with a big number of structures in comparison with the area surrounding it. Urban areas can be towns, localities or urban agglomerations but this term does not include rural settlements, like villages. Urban areas were created and developed in the wake of the process of urbanization. When one measures the extension to an urbanized area one contributes to analyzing the density of the population and of the urban expansion, when determining the urban and rural population.

Unlike the urban area, a metropolitan area includes not only the urban area but also the satellite towns, plus the intervenient rural lands that are socially and economically tied to the core of the urban town. In the case of urban agglomeration, the urban-geographical reality includes the town as such, and a territory that "bears" its direct influences, and together they are an urban agglomeration. This is the very embodiment of a gradual dispersion of the urbanized space that sets out from a central nucleus whereas its borders are constantly modified. A suburb is often defined as a residential area that surrounds the central area of an urban area of a town or a locality. The suburb is prevailingly an area of isolated single family houses. Some suburbs are politically autonomous, and most of them have a lower density than the neighbourhoods in the Centre of towns. Modern suburbs developed in the 20th century as a result of the improvement of roads and railways and the growing number of commuters to work. Suburbs tend to proliferate around towns that ideally have a lot of flat proximity lands. Any particular suburban area is related to the suburb, whereas the suburban areas as a whole are called outskirts, or slum districts. Usually suburbs are characterized by traffic jams and longer drives, as compared to the traditional districts. In Romania, this is due to some aspects: one must have a car since buses are not available as should be, distances are longer and 
there is a hierarchical system which is less effective in traffic distribution than the traditional grid of streets.

In suburbs, most of the rides from one structure to another need to integrate the cars in the collecting roads, regardless of how long or short the distance is. This is made up of a hierarchy of streets where whole districts and sub-units are dependent on one or two collecting roads. Since traffic is forcefully directed to these streets traffic becomes very busy. If there is a traffic accident on a collecting road or if a road is narrowed, and thus hampering the inflow of cars, the whole road system can be considered useless until the road block is resolved. The traditional texture of streets in the form of a grid allows for a bigger number of options and of alternative routes. The suburban system with a certain type of surface is also insufficient for cyclists or pedestrians. This encourages the use of cars even for smaller distances of some hundred meters (that might become several kilometres due to the street network).

A metropolitan area usually combines agglomeration (the adjoining built areas) with the peripheral areas not necessarily urban but closely related to the centre. These areas are also often known as ring roads for commuting and might go beyond the urban periphery depending on the definition used. This is usually an area that is not part of the town but it is connected to the town. The nucleus of a town in a poly-centre of a metropolitan area should be physically comparable to a conurbation that entails urban annexation.

In reality, the parameters of a metropolitan area, in both its uses, both official and unofficial, are not compatible. Sometimes they are a little bit different as compared to an urban area and in other cases they cover extensive regions that are poorly related to the traditional concept of a town as a single human settlement. The number of the population in the metro area is given by different sources and by territorial expansion. There are 315 towns with over a million inhabitants in the world. The metropolis plays the role of a capital city at a regional or national level. It is a very important centre economically, politically and culturally and is usually a centre of international communications.

The development of urban agglomerations is facilitated by a series of factors: the growing international trade, de-regulation of the financial markets, decentralization of production and re-location of production according to the emergence of less expensive sources and, obviously, the development of the knowledge economy - with the advanced applications of the information technology. In this way we witness the promotion of new models of "urban 
economics", which rely on the "urban functions and quality of life questions". Under these circumstances specialists focus both on the "core city" and the lay out of the "hinterland".

\section{Urban Policies}

According to some authors, "urban policies are economic policies implemented specifically at the urban level and they generally involve attempts to improve the attractiveness of urban and suburban areas as locations for investments. The sectors which are regarded as being the most sensitive to such small spatial scale variation are the real estate and property development sectors" (McCann, 2001) .

The phenomenon of globalization has also an impact on urban development by facilitating growing "competition between cities", which compels both the big urban centres and the smaller ones to develop strategies for urban development that should be viable and adjusted to the competition environment that is in permanent change. Hence, we have witnessed in the past two decades the "competitive planning programmes for global integration", created in towns both in economically developed countries and in developing countries, all being in a real race for capturing the "capital flows", meant to determine an increase in the living standards of its inhabitants. In some countries the attraction of foreign direct investments (FDI) has followed the establishment of some industrial theme areas - that provided a series of tax incentives and incentives of another nature. A relevant example for the urban development policy aiming at attracting FDI is the Pudong region, in China, a triangular area of $522 \mathrm{km2}$, in the area of the river Huangpu - Shanghai. Innovation of urban policies and responsiveness to the changes induced by globalization facilitated the creation and maintenance of an "urban culture" that is distinct in this region of China, thus attracting investors. In order to cope with the global competition, "cities have integrated as collective geographically located units", which was reflected in the expansion of the metropolitan areas and the emergence of "global city-regions" (Scott et all, 2001), as well as of "delta-metropolis" (Wu, Barnes, 2008). This new urban concept, of a neo-liberal nature, allowed for some regions and towns that did not have an overall strategy to be integrated in a coordinated unitary system which also facilitated an interaction of the constitutive elements, with beneficial effects at an economic, social and cultural level. 
Global city-regions emerged in the wake of some major modifications in the economic geography of the world due to the trans-national economic activities focused on the exploitation of the cheap resources of labour and materials. The deep-going political changes at the end of the $70^{\prime}$ ties contributed to the re-configuration of the internationalization of production in the multinational companies, changing in this way the geography of foreign direct investments (FDI). More and less economically developed countries have been more and more involved in this process, in spite of the fact that the level of the added value obtained by them was still reduced. Thus, a series of developing countries, among which China, have become the destination of some massive foreign direct investments. The new international division of labour and the new spatial distribution of foreign direct investments created the prerequisites for the creation of global city-regions in the developing countries (among which China, as well). One of the most wide spread strategies for the attraction of foreign investment in these regions was the setting up of special (open) economic areas or industrial parks.

The metropolitan spaces extended by interaction are now connected by high speed transport corridors which cover some hundred kilometres from "core metropolitan centre". A city region includes tens or maybe hundreds of jurisdictional subdivisions (municipalities, counties and townships), each of the sub-divisions representing just one part of the functioning city-region. There is a growing number of metropolitan centres in the global city-region and they are dominated by imposing buildings that host the head offices of international companies in the fields of production and services. The entire area is served by modern airports and adequate infrastructure, university campuses and associated scientific parks, theme parks for entertainment and huge supermarkets. The so-called peri-urban areas have become areas of specific industrial activities, like: industrial parks or areas for processing of exports, hosting operations based on intensive work, namely, for assembling the components coming from the advanced economies.

Global city-regions function as a magnet for low-wage migrant labourers. Due to their location, the competitive advantages, many of them having attracted massive foreign direct investments and representing territorial platforms for economic restructuring. In the opinion of specialists (Scott et all, 2001) , "global city-regions are regional engines of the global economy". The basis for the formation of the global city-regions, as it comes out of the 
experience of China, has been provided by the development of economic clusters. Plus that the local governments at provincial and lower levels have strongly supported economic polarization following the organization of the urban space and the granting of zonal incentives in order to attract foreign direct investments.

The next stage however brought in the problem of counteracting competition of other "mega urban regions". In this context, the competent authorities have developed a "global competitive planning" in the form of "urban mega-projects", of big dimensions and emblematic for the areas they referred to. Although these competent authorities have worked together - in principle - at a national, regional and town level, a series of conflicts have inevitably emerged in the course of this process, in the management of the "urban mega-projects". Although the local authorities had an entrepreneurial attitude there was still the tendency to retain the old traditional "planning" activities concentrated on the old regulations on using the land, the transport routes and the infrastructure, in general, neglecting the primordial objective that of identifying the opportunities of the global market and of assisting foreign investors in "exploiting" the advantages offered by the "urban mega-projects". As specialists have clearly mentioned ( $\mathrm{Wu}, \&$ Barnes, 2008), "the creation of urban mega-projects is singleminded planning". In this way expectations are that these giant projects will create a spatial design that should provide an adequate frame for the use of lands, at a maximum level of profitability for foreign investors. That is the very reason why "through central planning requirements", the achievement of urban mega-projects was possible due to coordination in the governmental system. As international economic conditions develop "spatial planning" should be reconsidered. Anyway, at a world level, the "urban mega-projects" like the ones in Asian World City in Manilla, Pacific Place in Vancouver and Pudong in Shanghai represent models for a beneficial reorientation of the initial international image of towns that hosted "urban mega-projects". One should not ignore however the secondary effects in the process of image transformation, namely, the change in the daily life of the inhabitants and of the spaces used by the community, in favour of some global models of production and consumption.

The emergence of mega cities of over 10 million inhabitants or of the new type of urban agglomeration in the form of Extended Metropolitan Regions, particularly in Asian countries can be explained by the influence of economic globalization. The sustainable development of the environment of the mega cities has become of utmost importance following the high consumption of land and energy, pollution of water and soil and, last but not least, the intensification 
of social problems. However, sustainability has become a problem for urban development as well, and has become sensitive in the context of trans-national business. Foreign investment has been used by some Asian countries, the most frequent example being that of China, for the very successful implementation of the urban local plans.

Literature (Maier, Ondos, \& Sedlacek, 2008) particularly in the urban policies, refers to the urban zoning policy (for instance, the geographical zoning of activities; this category might include elements like those presented above) and another type of policy applied for urban development, and to the urban regeneration policy, respectively. These polices are meant to encourage the "redevelopment of the downtown urban areas and to counter the out-migration, loss of population, decline of industrial and manufacturing sites"( Maier, Ondos, \& Sedlacek, 2008)).

Urban regeneration policy has become a fashionable concept in the 80 'ties having been initially applied in Great Britain and subsequently in other West-European countries. Various forms of public support (Healy, 1991) have been used in order to attract private investment in the process of urban regeneration, with subsequent effects like: creation of new jobs, improvement of land management. The opening of the respective market, which implied the involvement of the public sector, led to coordination of the activities for development, to the overall concept on land management, to granting of subsidies -which minimized the risk of investment - and created plentiful of opportunities for the private sector. The promotion of private public partnerships, as well as "property interests” have been recognized as major elements during the process of redevelopment ( $\mathrm{He}, \mathrm{Wu}, 2005)$. Such initiatives were focused on the city centre or waterfront. As some authors have asserted (He, \& Wu, 2005), "property development has played an important role in reconstructing urban spaces and producing urban landscapes, in giving cities an identity, ... it is ... obvious how it fundamentally affects the urban economy".

\section{Relation between urban (re)development and urban governance}

Specialists have tried to lay stress on the relation between urban (re)development and urban governance. Examples to this effect are the cities in USA whose economic renewal and growth have been the outcome of a good coordination of activities inside them, carried out by the property owners and 
developers, and supported in their turn by the local media, universities and cultural establishments. According to the theory on urban environment, the complex modern urban governance should also involve the non-governmental actors in regulating the development of the respective locality. In this context, big coalitions were established between the local government and the business environment, whereas the autonomous and independent participation of the respective actors has been given up.

Besides the Western economies, a special example for the spectacular results obtained in urban regeneration is China in its period of transition to the market economy and in the post-reform period. One of the most successful property development projects in Shanghai carried out in the past few years is Xiantiandi - part of the redevelopment area of Taipingqiao, its name being almost pre-determined as in translation it means „peace bridge”.

Since during the Cultural Revolution (1966-1976) urban development stagnated completely the urban landscape became deplorable. At the start of the Economic Reform in 1978 urban (re)development as such became one of the most attractive targets for most of the Chinese towns, for housing reconstruction, infrastructure construction and improvement, respectively. At the same time we witness industrial restructuring which entails the modification of the urban aspect, since factories are moved outside of the towns and services developed especially inside the towns. The reform of land use and of housing privatization laid value on both the urban land and the notion of housing, and that facilitated the accelerated real estate development. Due to the initially insufficient funds for urban redevelopment, local authorities worked out aggressive strategies for attracting private investment. "Redevelopment of old and dilapidated areas fas been turned into large-scale property development" (He, Wu, 2005). According to specialists (ibidem), urban redevelopment in China changed dramatically, from being supported by the government to relying on „property development”.

Therefore, attracting private investment, both autochthonous and foreign, became crucial for economic growth and urban development. In China we witnessed an impressive process of decentralization; most of the income coming from land administration as well as the most important decisions on land use were made by the local authorities. At the same time the allocation of financial resources to local authorities is under the direct coordination of the central administration. In this context it is noticeable that the concept of entrepreneurial governance was introduced in urban development and the opening of the market and the promotion of competition were encouraged. The 
process of attracting investment stays as transparent as could be for the central state whereas the local authorities create all the conditions for urban redevelopment. "Property-led redevelopment is thus widely deployed as a development tactic" in China. (He, \& Wu, 2005). Naturally, there are some peculiarities by comparison to practices in field in the Western economies. For instance, adoption of a land lease system allowing for the transfer of land use rights on the market, whereas the ownership of urban land is retained. Under these circumstances start ups need to purchase land from the local government and to pay some land leasing charges. This is a wide scope issue that can be subject to a separate study.

A case mentioning in urban redevelopment is that of Hong Kong, the city whose urban development strategy - that provided a limited role to the community in this process - was successful only until the star of the financial crisis in Asia, in 1997. Redevelopment projects carried out in Hong Kong so far could not resolve the problem of buildings in an advanced stage of degradation and neither of their tenants. This experience, specialists say (Mee Kam Ng, 2002), shows that "the lack of coordination between different parts of government and the lack of mandate by the renewal agencies over the appropriate government departments, are the major reasons for" not achieving the process of urban redevelopment at the estimated standards. This experience proves that only an "integrated urban approach" can improve the urban landscape, with beneficial socio-economic effects. The government cannot rely only on private initiative, and hence it is necessary to create some neighbourhood networks as well as cooperation between different community-based groups. In the opinion of specialists it is in this way alone that an urban landscape that should observe the history of the place and how people use the space can be created. Moreover, literature says (Drakakis-Smith, 1976) that „more consideration must be given to understanding the mechanism and characteristics of slum districts themselves before any change in policies can be brought about".

The variety of real cases shows that there are no universal strategies for urban regeneration and development, since they have to be adjusted to the local specifics and traditions, taking into account however the tendency towards urban development at a European and obviously at a world level, considering that globalization affects all economic activities. 


\section{Romanian Urban Particularities}

Similar to most of the former communist countries, Romania has no tradition in regional development policy and, implicitly, in the urban development policy as well. Consequently, in the second half of 2007, the Romanian officials (namely the Ministry of Development, Public Works and Dwellings - Strategies and Public Policies General Division). To the elaboration of this strategic concept have also collaborated the "Urban Proiect" National Institute of Research and Development and the "Ion Mincu" University of Architecture and Urbanism) have submitted for consultation to a specialists group a project regarding the achievement of the "Strategic concept of territorial development of Romania over the period 2007-2030". Later on, the strategic objectives, the national projects packages for each objective, as well as the aspects regarding the technical assistance required for implementation will be detailed.

The start of the process of completing the "Strategic concept of territorial development of Romania over the period 2007-2030" circumscribes along the line of the requirements formulated in the EU documents, namely to elaborate strategic documents able to be used by the member states for the long-term territorial development.

The aim of presenting the "Strategic concept of territorial development of Romania over the period 2007-2030" was, on the one hand, to reveal the longterm vision of territorial development of Romania and, on the another hand, to provide, in the spirit of the European documents, a technical foundation to the support of improving the capability of absorbing the EU community funds - with the aim to diminish the development gaps of Romania as against the EU advanced member states.

The strategic objectives of this document were:

- Connection with the European network of territorial development poles and corridors,

- Structuring and development of the urban localities network,

- Affirmation of the urban-rural solidarity adequate to different categories of territory,

- Strengthening of the trans-Carpathian links as support of regional development,

- Turning to the best account of the natural and cultural heritage. 
In fact, the new national concept of European inspiration stressed upon the integrated urban development, and upon the development of a metropolitan network in Romania.

The integrated urban development, based on investments in local infrastructure, stimulation of the business environment and turning to the best account of the local resources was in fact the first priority axis of the Regional Operational Program 2007-2013. Through this program (ROP), Romania will receive the largest funding as compared to funding for other objectives, namely 1.3 billion euro for urban development. In this sense, there are many preoccupations at the Ministry of Development, Public Works and Dwellings for the sustainable development of towns in accordance with the EU Sustainable Development Strategy. On the basis of a strong partnership with academia, especially with the University of Architecture it is pursued the elaboration of integrated urbanism plans and coordinated actions of all the persons and institutions involved in the urban development process.

This first priority axis, called "Support for the sustainable development of towns, urban poles for growth" that is found within ROP has as a first objective (as results from its title), the increase in life quality through regeneration, revitalization of towns with economic growth potential.

The integrated urban development represented an important goal also for the next programming period, through the Regional Operational Programme 2014-2020. In this respect we have to mention its Priority Axes focused on supporting sustainable integrated urban development and regeneration of deprived urban areas and also on developing cultural heritage and tourism as drivers for local economic development, and of course on improving regional connectivity.

\section{The urban network in Romania}

The urban network is more densely populated in the Centre Region (57 towns and cities), because of Transylvania historically having a better-structured urban network and in the South (49 towns and cities), but this because the Region simply includes the highest number of counties (7). There is a relatively well-balanced distribution of large towns across the country. 
In Romania, the new national conception by European inspiration, focuses on integrated urban development, and on that of metropolitan networks development (Botezat, \& Păuna, 2016).

Although Romania has many cities (Small and medium), these are not working as in a network, because there are no economic relations between them or between urban centers and surrounding areas. The development model of these urban centers has been designed independently of each other. There is even the danger that mono-industrial towns, to detach from the normal economic circuit.

Oradea was one of the first cities in Romania to adopt a City Development Strategy; It's goals are focusing on the strategy that outlines five key development policies: Economic Development, Housing, Public Services, Environment and Urban Revitalization. In this context, it was created also a Metropolitan Development Corridor. Oradea and the adjacent seven communes of Biharia, Bors, Cetariu, Osorbei, Nohorid, Sanmartin and Santandrei are defining their long-term competitive position within the European and Romanian road corridors. Thus Oradea in cooperation with Bihor County has facilitated important activities to support this objective including the development of a cooperative agreement with the seven adjacent communes to increase intercommunal cooperation.

This new approach to formalizing cooperation at a metropolitan level among Bihor county, Oradea and the surroundings communes is a first in Romania.

\section{Final remarks}

Nowadays there is a strong obvious link between different challenges that urban areas are forced to face such as: economic, social, demographic, climate and environmental. Thus, to achieve a successful urban development one needs to take an integrated approach. Physical urban renewal objectives are not to be implemented alone but along other measures promoting economic development, social inclusion, education and environmental protection. The key element in the development of a strong partnership between citizens, local authorities, the civil society, and government is mutual aid (Botezat, \& Păuna, 2016). Local experience and expertise should come first when trying to identify proper solutions for long term good results. 
Under these circumstances it became obvious that it must exit a proper relation between urban development and urban governance and that a smart city has more dimensions (according to specialists and the European documents as in the figure below).

Figure 1. Dimensions of smart city - part of urban development policy

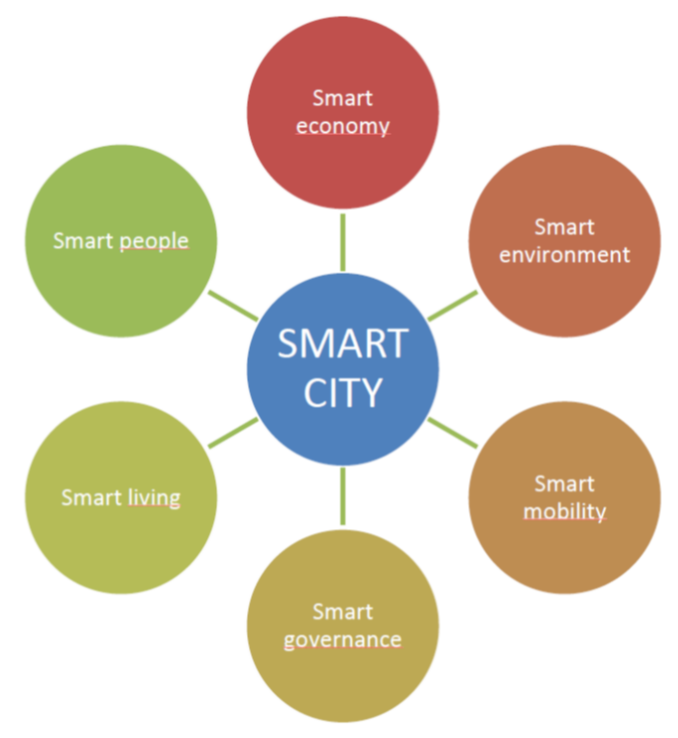

Source: www.smart-cities.eu (accessed on January 15, 2015)

The elements of the new approach of integrated urban development should focus on:

- integrated urban development strategies with a more holistic approach

- stronger focus on urban development at programming level:

- investment priorities tuned to facilitate tackling urban challenges

- improved tools to deliver integrated actions

- increased responsibility for urban authorities

- strengthened networking (Botezat, \& Păuna, 2016). 


\section{References}

[1] Botezat, E., \& Păuna, C.B. (2016). Integrated urban regional development; Case study Inter-communal cooperation within Bihor County, Hungarian Regional Science Association 14th Annual Meeting ,The Role of Small and Medium Sized Cities in Regional Development, 15-16 September 2016, Partium Christian University, Oradea

[2] Drakakis-Smith, D.W. (1976).Urban Renewal in an Asian Context: A Case Study in Hong Kong, in Urban Studies, 13, pp.295-305.

[3] He S., \&Wu F. (2005). Property-led redevelopment in post-reform China: a case study of Xiantiandi redevelopment project in Shanghai, Journal of Urban Affairs, vol. 27, no. 1, (1-23), p. 2

[4] Healy, P. (1991). Urban Regeneration and the Development Industry, in Regional Studies 25(2), pp. 97-110.

[5] Maier G., Ondos, S., \& Sedlacek S. (2008). "Real Estate Development in Bratislava and Vienna", the 48th Congress of ERSA, Liverpool, p. 7

[6] McCann, Ph. (2001).Urban and Regional Economics, New York: Oxford University Press.

[7] Ng, Mee K., Kervic Chan, \& Peter H. (2002). Sustainable Development in China: From Knowledge to Action, in International Journal of Environment and Sustainable Development 2, no I, pp. 36-61.

[8] Scott, J. A., et al. (2001). Global City-Regions; Trends, Theory, Policy, Los Angeles: Oxford University Press.

[9] Wu J., \& Barnes T. (2008). Local planning and global implementation: Foreign investment and urban development of Pudong, Shanghai, Habitat International 32 (364-374), pp. 365.

[10] Regional Operational Program 2007-2013, Guvernul României, Ministerul Dezvoltării, Lucrărilor Publice și Locuințelor, Regional Operational Program 2014-2020, Ministerul Dezvoltării. 